\title{
Review
}

\section{HMGB1, an alarmin promoting HIV dissemination and latency in dendritic cells}

\author{
M-L Gougeon ${ }^{*, 1}$, M-T Melki ${ }^{1}$ and H Saïdi ${ }^{1}$
}

Dendritic cells (DCs) initiate immune responses by transporting antigens and migrating to lymphoid tissues to initiate T-cell responses. DCs are located in the mucosal surfaces that are involved in human immunodeficiency virus (HIV) transmission and they are probably among the earliest targets of HIV-1 infection. DCs have an important role in viral transmission and dissemination, and HIV-1 has evolved different strategies to evade DC antiviral activity. High mobility group box 1 (HMGB1) is a DNA-binding nuclear protein that can act as an alarmin, a danger signal to alert the innate immune system for the initiation of host defense. It is the prototypic damage-associated molecular pattern molecule, and it can be secreted by innate cells, including DCs and natural killer (NK) cells. The fate of DCs is dependent on a cognate interaction with NK cells, which involves HMGB1 expressed at NK-DC synapse. HMGB1 is essential for DC maturation, migration to lymphoid tissues and functional type-1 polarization of naïve $T$ cells. This review highlights the latest advances in our understanding of the impact of HIV on the interactions between HMGB1 and DCs, focusing on the mechanisms of HMGB1-dependent viral dissemination and persistence in DCs, and discussing the consequences on antiviral innate immunity, immune activation and HIV pathogenesis.

Cell Death and Differentiation (2012) 19, 96-106; doi:10.1038/cdd.2011.134; published online 28 October 2011

Facts

- High mobility group box 1 (HMGB1) is a nuclear DNAbinding protein actively released by innate immune cells in response to exogenous pathogen-derived molecules, acting as a danger signal and triggering inflammation.

- HMGB1 is a proinflammatory cytokine that is essential for maturation of dendritic cells (DCs), their migration to lymphoid tissues and Th1 polarization of naïve T cells.

- HMGB1 signals by binding to Toll-like receptor 4 (TLR4) to activate MyD88-dependent nuclear translocation of NF- $\kappa \mathrm{B}$, which upregulates the expression and release of cytokines and other inflammatory mediators.

- HMGB1 is expressed at the synapse between NK cells and DCs, it is pivotal during NK-DC cross talk, promoting DC maturation and protecting them from lysis.

- HMGB1 triggers human immunodeficiency virus (HIV) replication in latently infected primary myeloid cells.

\section{Open Questions}

- What are the molecular mechanisms involved in vivo in the disruption of NK cell-DC cross talk during chronic HIV-1 infection, and what are the consequences on both NK cell killing activity and DC-dependent promotion of adaptive immune responses?

- Does HMGB1 has a role in the trans-infection of T lymphocytes with HIV-1 through the exosome-dissemination pathway?

- Given that HMGB1 can combine with LPS to trigger TLRs, and TLR-mediated immune activation results in the production of proinflammatory cytokines, to what extent does HMGB1 contribute to generalized immune activation and disease progression in HIV-1-infected individuals?

- What is the contribution of HMGB1 to HIV dissemination and the establishment of HIV reservoirs in DCs?

- Would the specific targeting of c-FLIP or c-IAPs in DCs contribute to the depletion of HIV-1 reservoirs?

- Given the expression of HMGB1 and its receptor RAGE in active neurological diseases, including multiple sclerosis and Alzheimer's disease, does it has a role in HIV-associated neurological disorder?

High-mobility group box 1 protein (HMGB1) (also known as amphoterin or HMG1) was originally defined as a non-histone nucleosomal protein that is important for the regulation of transcription. It is a 215 amino-acid protein, encoded on chromosome $13 q 12$, which is highly conserved between

\footnotetext{
${ }^{1}$ Antiviral Immunity, Biotherapy and Vaccine Unit, Infection and Epidemiology Department, Institut Pasteur, Paris, France

${ }^{*}$ Corresponding author: M-L Gougeon, Antiviral Immunity, Biotherapy and Vaccine Unit, Infection and Epidemiology Department, Institut Pasteur, 25 rue du Docteur Roux, 75724 Cedex 15, France. Tel: + 3314568 8907; Fax: + 3314568 8909; E-mail: marie-lise.gougeon@ pasteur.fr

Keywords: dendritic cell; HIV; HMGB1; natural killer cell; TRAIL

Abbreviations: ASC, apoptotic speck protein containing a caspase recruitment domain; CpG ODN, cytosine-phosphate-guanosine oligodeoxynucleotides; DAMPs, damage-associated molecular patterns; DCs, dendritic cells; cFLIP, cellular FLICE-inhibitory protein; HIV, human immunodeficiency virus; HLA, human leukocyte antigen; HMGB1, High mobility group box 1; cIAP, cellular inhibitor of apoptosis protein; LPS, lipopolysaccharide; NK, natural killer cells; PAMPs, pathogen-associated molecular patterns; PRRs, pattern recognition receptors; RAGE, receptor for advanced glycated endproducts; SIV, simian immunodeficiency virus; TLRs, Toll like receptors; TRAIL, TNF-related apoptosis-inducing ligand

Received 05.5.11; revised 03.8.11; accepted 12.8.11; Edited by G Melino; published online 28.10.11
} 


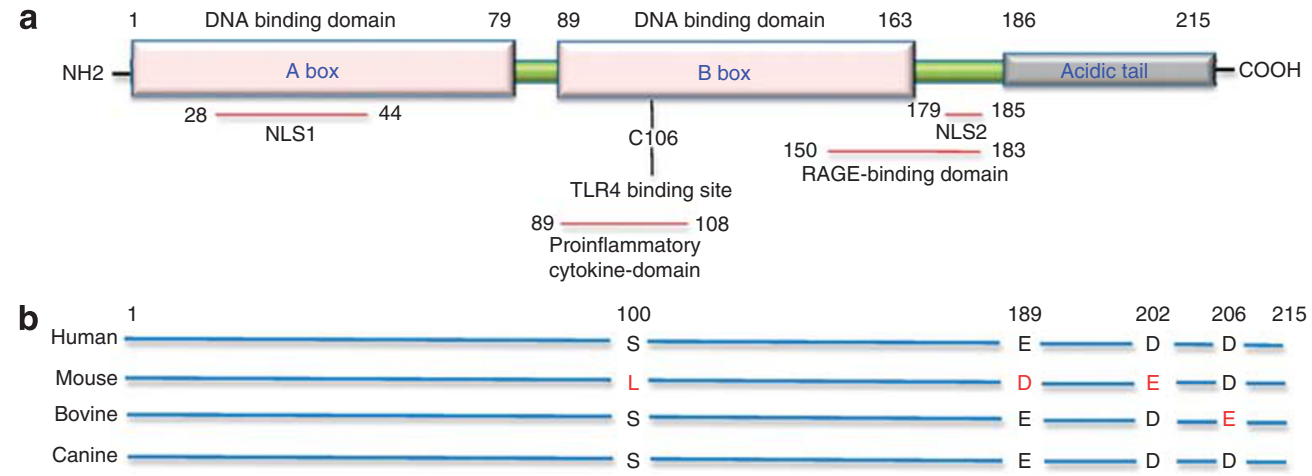

Figure 1 Structure of the HMGB1 protein. (a) HMGB1 is a $25-\mathrm{kD}$ a conserved chromosomal protein of 215 amino acids. It is organized in three domains made up by two positively charged homologous DNA-binding structures ( $\mathrm{A}$ and $\mathrm{B}$ box), and a negatively charged acidic tail composed of 30 glutamic and aspartic acids, exclusively. There are two positively charged nuclear-localization signals, including amino-acid sequence segments $28-44$ for NLS1 and 179-185 for NLS2. Amino-acids 50-183 segment in the C-terminus of HMGB1 is responsible for RAGE binding. The extracellular cytokine activity resides within the B box, and it can be antagonized by truncated $\mathrm{A}$ box domain. The cysteine in position 106 in the B box is indispensable for HMGB1 to activate cytokine release, as shown by selective mutation. The C-terminal acidic tail is required for transcription stimulatory function of HMGB1. (b) The primary HMGB1 sequence is $98.5 \%$ identical in all mammals. Comparison of human HMGB1 to the murine counterpart shows two differences in the acidic tail and one amino-acid change in the B box, whereas bovine HMGB1 shows only one amino-acid change in the acidic tail, and canine HMGB1 shows $100 \%$ homology with human HMGB1 (adapted from Murua Escobar et al. ${ }^{96}$ )

species $(99 \%$ species homology between rodents and humans). HMGB1 contains two internal repeats of positively charged domains, the $\mathrm{A}$ - and $\mathrm{B}-\mathrm{Box}$, in the $\mathrm{N}$ terminus, and a negatively charged $\mathrm{COOH}$ terminus (Figure 1). The two boxes bind to the minor groove of chromatin, thus modifying DNA architecture. ${ }^{1}$ This facilitates the binding of regulatory protein complexes to DNA such as $\mathrm{V}(\mathrm{D}) \mathrm{J}$ recombinase ${ }^{2}$ and p53-p73 transcriptional complexes. ${ }^{3-5}$ In its resting state, the acidic tail of HMGB1 interacts with specific residues in the A-Box and B-Box, forming an extended and flexible segment, shielding them from other interactions that might occur before HMGB1 binds DNA. ${ }^{6}$ HMGB1 likely has a role in DNA repair and replication. HMGB1 overexpression, which is observed in many tumors, accelerates cell cycle progression, and recent data suggest that endogenous HMGB1 is a critical pro-autophagic protein that enhances cell survival ${ }^{7}$ and that HMGB1-induced autophagy promotes chemotherapy resistance in leukemia cells. ${ }^{8}$

The discovery by Kevin J Tracey et al. (1999) in a mouse model of endotoxaemia that lipopolysaccharide (LPS)activated macrophages release HMGB1, but later than secretion of the pro-inflammatory cytokines TNF- $\alpha$ and interleukin 1 (IL-1), and that protection against endotoxin lethality could be obtained by administration of anti-HMGB1 antibodies ${ }^{9}$ has revealed that HMGB1 is a proinflammatory mediator able to alert the immune system to tissue damage and to trigger an immediate response. The term 'alarmin' has been proposed to differentiate the endogenous molecules that are very rapidly released or produced in response to microbial infection or tissue injury, and act as potent effectors of innate defense. ${ }^{10}$ Alarmins have antimicrobial, enzymatic or chromatin-binding activities and they share common features, including their rapid passive release from necrotic cells or secretion from cells of the innate immune system (macrophages, natural killer (NK) cells) in response to infection, they bind to TLRs and receptors of antigen-presenting cells such as DCs, thus promoting adaptive immunity, and they are involved in the reconstruction of tissues destroyed secondary to inflammation. ${ }^{11}$ Based on these criteria, a list of putative alarmins has been proposed, including the defensins, eosinophil-derived neurotoxin, thymosins, annexins, HSPs, or IL-1 $\alpha .{ }^{12}$ HMGB1 remarkably fulfills these criteria and it is probably the best-characterized alarmin. The crucial role of HMGB1 not only in response to infection, injury and inflammation, but also its pathological effects in many diseases have recently challenged important questions regarding its biological activities and pathological effects.

Recent studies have established the involvement of HMGB1 in not only acute and chronic inflammatory conditions, including sepsis, ${ }^{13}$ rheumatic diseases, ${ }^{14}$ or SLE, ${ }^{15}$ but also viral infectious diseases, such as that induced by SARS, hepatitis viruses, influenza viruses ${ }^{16}$ or HIV. ${ }^{17}$ It is currently unclear whether HMGB1-mediated inflammatory response contributes to the pathogenesis of various viral diseases, but it has been suggested to be involved in SARS-associated injurious pulmonary inflammatory response, persistent liver injury in hepatitis patients, or pathogenesis of West Nile encephalitis. ${ }^{18}$ Regarding HIV infection, elevated plasma levels of HMGB1 were detected during progressive HIV-1 infection, positively associated with viral replication. ${ }^{17}$ In vitro, HMGB1 may trigger or inhibit HIV-1 replication, depending on the target cell and the microenvironment. ${ }^{19,20}$ Recent studies analyzed the impact of HMGB1 on the fate of HIV-1-infected DCs, and the data suggested not only a possible contribution of this protein to the functional impairment of DCs but also to HIV dissemination and persistence. ${ }^{21,22}$ This review will discuss the mechanisms whereby HMGB1 contributes to innate immunity by regulating maturation and functions of DCs but also how it may contribute to viral latency and HIV disease pathogenesis.

\section{HMGB1, a DAMP that Likes DCs}

HMGB1, a sentinel for nucleic-acid-mediated response in DCs. During microbial infection, the activation of innate immune responses by DNA and RNA is essential to protective immune responses and is mediated by the 
transmembrane TLRs and cytosolic receptors. ${ }^{23}$ TLRs belong to a family of pattern recognition receptors (PRRs) that have essential roles in innate immunity. They are a class of single-membrane-spanning receptors that have the ability to recognize structurally conserved molecules from bacteria. Engagement of TLRs activates the immune response. HMGB proteins bind to all immunogenic nucleic acids and have recently been identified to serve as universal sentinels for nucleic-acid-mediated innate immune responses. ${ }^{24}$ Activation of macrophages or DCs with microbial cytosinephosphate-guanosine (CpG)-DNA, resulting in secretion of proinflammatory cytokines, involves TLR9 initially localized in the endoplasmic reticulum (ER). The mechanism of TLR activation by CpG-DNA was recently discovered and HMGB1 was found to have a crucial role. HMGB1 binds to CpG-DNA and receptor for advanced glycated endproducts (RAGE), the first identified receptor for HMGB1, and this DNA-protein complex preassociates with TLR9 in the ER-Golgi intermediate compartment, thus accelerating the delivery of microbial DNA to TLR9 and leading to the recruitment of the TLR adaptor molecule MyD88. ${ }^{25}$ Thus, HMGB1 and RAGE are pivotal for TLR9-dependent induction of genes encoding type I interferon after stimulation of DCs with DNA-containing complexes. Ablation or depletion of HMGB1 impairs redistribution of TLR9 to early endosomes in response to CpG-oligodeoxynucleotides (ODN), leading to a decreased response to CpG-ODN, but which could be complemented by extracellular HMGB1. ${ }^{25}$ In addition, HMGB1 was found to be a key factor in immune complex-triggered activation of autoreactive B cells and the induction of type I interferon by plasmacytoid DCs, thus possibly contributing to SLE. ${ }^{25}$

HMGB1, a cytokine that initiates host defense. HMGB1 is a nuclear protein and, to function as a cytokine, it must be released in the extracellular milieu. This occurs either via passive release from necrotic cells, ${ }^{26,27}$ or by active secretion by cells of the innate immune system. Wang et al. $^{9}$ first reported that HMGB1 was liberated from macrophages stimulated with LPS, and that HMGB1 had an important role in experimental sepsis. HMGB1 secretion from LPS-primed macrophages was shown to require the inflammasome components apoptotic speck protein containing a caspase recruitment domain (ASC), caspase 1 and NALP3. ${ }^{28}$ Monocytes, macrophages and immature DCs (mDCs) secrete HMGB1 in response to LPS, TNF- $\alpha$, or IL-1 $\beta$ stimulation. $^{29}$ IFN- $\gamma$ can induce HMGB1 release from macrophages that, at least in part, requires induction and signaling through TNF- $\alpha{ }^{30}$ Secretion of a nuclear protein requires a tightly controlled relocation program. Several forms of post-translational modifications, such as acetylation, phosphorylation and oxidation result in the accumulation of HMGB1 in the cytosol. ${ }^{31-34}$ Upon activation with LPS, monocytes and macrophages acetylate HMGB1 extensively, allowing its relocalization from the nucleus to the cytosol, and further concentration into secretory lysosomes. ${ }^{35}$ Thus, because it does not contain a leader sequence, HMGB1 is secreted via a non-classical vesiclemediated secretory pathway.

A second pathway of HMGB1 nuclear/cytoplasmic shuttling has been reported involving phosphorylation, ${ }^{33}$ mediated by protein kinase C. ${ }^{36}$ In neutrophils, HMGB1 is post-translationally methylated, which alters its conformation and weakens its DNA-binding activity, causing its cytoplasmic localization. ${ }^{34}$ Recently, HMGB1 has been shown to undergo oxidation that may have the potential to modulate various aspects of its function, including subcellular localization, interaction with DNA, cytokine activity and proinflammatory activity. ${ }^{37}$ Indeed, induction of immunological tolerance by apoptotic cells was shown to require caspase-dependent ROS production by mitochondria, which oxidized the danger signal HMGB1, and thereby neutralized its damage-associated molecular pattern molecule (DAMP) function, including the ability to activate DCs. ${ }^{38}$ From the reverse perspective, in necrotic cells that do not generate ROS and provide fully active HMGB1, treatment with $\mathrm{H}_{2} \mathrm{O}_{2}$ inactivates the DAMP function of the protein. Thus, DAMP is released and can work, but briefly and in a short range, until it gets oxidized. This restricts its activity temporally and spatially, preventing a prolonged stimulation of its targets and thereby limiting inflammation. ${ }^{39}$

HMGB1 is essential for DC maturation, migration and Th1 polarization. Inflammatory signals activate antigenpresenting DCs, which undergo a differentiation process referred to as maturation and migrate to secondary lymphoid organs. HMGB1 has a crucial role in this process, acting as a chemoattractant for immature DCs (iDCs) that involves RAGE, and further inducing DC maturation, as shown by the upregulation of the surface markers CD80, CD83, CD86 and human leukocyte antigen (HLA)-A, B, C, and DC production of cytokines, including IL-6, CXCL8, IL-12p70 and TNF- $\alpha .{ }^{11,40}$ The mobilization of DCs from peripheral tissues is critical for the establishment of T-cell-dependent immune responses or tolerance, because the physical interaction of DCs with naive $\mathrm{T}$ cells takes place in the T-cell areas of lymph nodes. Importantly, in vivo homing of DCs to draining lymph nodes depends on RAGE, ${ }^{41}$ a finding consistent with the in vitro upregulation of the CCR7 and CXCR4 receptors upon autocrine secretion of HMGB1 by mature myeloid DCs. ${ }^{40}$ Thus, the autocrine/paracrine release of HMGB1 and the integrity of HMGB1/RAGE pathway are required for the migratory function of HMGB1. Moreover, HMGB1 secreted by DCs is required for clonal expansion, survival and functional Th1 polarization of naïve $T$ cells, which occurs through the secretion of proinflammatory cytokines, including IL-12, IL-18 and IFN- $\gamma^{42,43,21}$ In the presence of inhibitors of HMGB1 or of RAGE, DC activated with pathogen-associated molecular patterns (PAMPs) fail to mature $^{43}$ (Figure 2).

The inflammatory properties of HMGB1 depend on the ability to complex with soluble moieties, including nucleic acids, microbial products (LPS), cytokines (IL-1 $\beta$ ) and chemokines. Campana et al. ${ }^{44}$ reported that HMGB1 secretion is required for CXCL12 (SDF-1)-dependent migration of DCs. In addition, HMGB1 protects the conformation of CXCL12 in a reducing environment, a state existing in the draining lymph node. However, only a partial inhibition of DC migration was observed in the presence of a CXCL12 inhibitor or HMGB1 A box, suggesting that multiple receptors are responsible for mediating the DC response to the HMGB1/ 


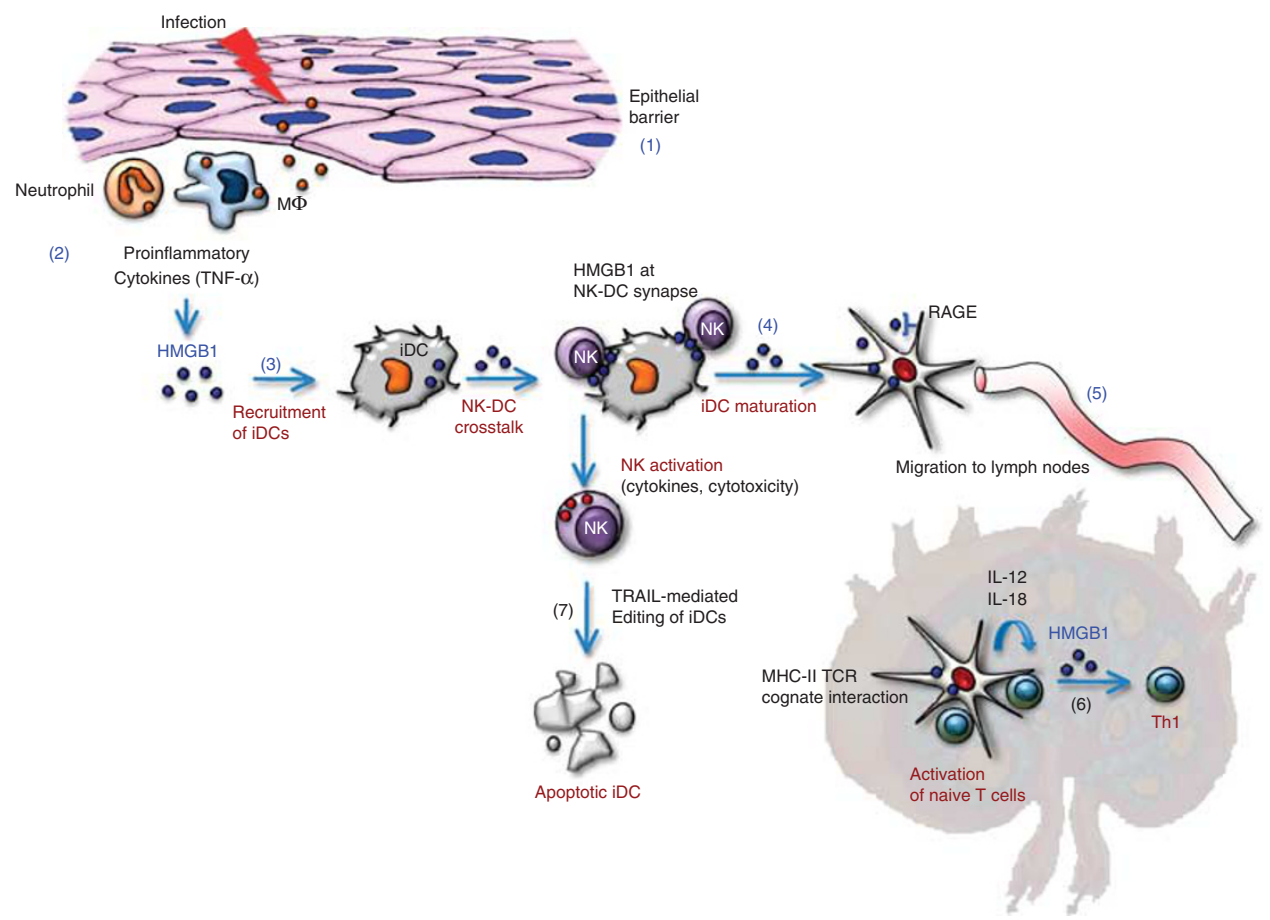

Figure 2 HMGB1-mediated cross talk between DCs and NK cells is pivotal to DC maturation and further induction of adaptive immunity. The disruption of an epithelial barrier allows invasion of microbial pathogens, which elicit an innate response at the site of infection (1). Neutrophils and macrophages infiltrate the site of tissue infection and release alarmins, including HMGB1 (2). HMGB1 recruits iDCs, resulting in an increase in local mobilization of iDCs (3). Functional DC maturation requires a cross talk with NK cells, which involves HMGB1 expressed at NK-DC synapse (4). Immature to mDC conversion allows DCs to migrate to secondary lymphoid organs (5) and contributes to the enhanced uptake, processing and presentation of microbial antigens to naïve T cells, thus polarizing a Th1 response (6). This T-cell response involves IL-12 and IL-18 released by mDCs. Cognate interaction between NK cells and DCs may also lead to the selective killing of DCs that are not appropriate for antigen presentation to T cells (7). This editing process, which involves TRAIL, allows NK cells to control the quality of DCs, thus regulating adaptive immunity

CXCL12 complex. An interesting study performed in CD24deficient mice revealed how the host distinguishes between danger versus pathogen PAMPs. ${ }^{45}$ The proinflammatory activity of HMGB1 is regulated by CD24, which associates with HMGB1, thus inhibiting NF-kappa B activation occurring through CD24 association with Siglec-10. Thus, this CD24Siglec-10 pathway protects the host against a lethal response to pathological cell death, but it would allow an appropriate response to invading pathogens. ${ }^{45}$

\section{Viral Piracy: HIV Targets DCs for Viral Transmission and Persistence}

DCs, pivotal to adaptive immunity, are early targets of HIV. All lentiviruses can infect macrophage lineage cells in which they generate a persistent infection. HIV-1 has developed a broader tropism leading to preferential infection of $\mathrm{CD}^{+} \mathrm{T}$ cells, which are progressively destroyed both as a direct viral cytopathic effect and a bystander induction of apoptosis in uninfected cells. ${ }^{46}$ Studies in animal models have revealed that critical events to establishing systemic infection take place very quickly at the mucosal portal of entry. Following mucosal exposure to high doses of simian immunodeficiency virus (SIV), the virus can cross the mucosal barrier and it establishes within 3-4 h a small founder population of productively infected cells. ${ }^{47,48}$ Infection then expands locally before virus detection in the draining lymph node, and systemically throughout the secondary lymphoid organs. ${ }^{49}$ In vivo, resting CD4 T cells are the initially infected cells in lymphoid tissues. ${ }^{48}$ However, the first cells to be infected at the mucosa are the intraepithelial DCs, as shown in vivo in the genital tract of rhesus macaques $1 \mathrm{~h}$ after intravaginal inoculation of SIV, and infected DCs reach the draining lymph nodes $18-24 \mathrm{~h}$ after SIV exposure, much earlier than CD4 ${ }^{+} \mathrm{T}_{\text {cells. }}{ }^{50}$

As sentinels, DCs are crucial for the generation of antiviral immunity. They are the most potent antigen-presenting cell in the immune system owing to their superior capacity for acquiring and processing antigens for presentation to $T$ cells and their potential to express high levels of the co-stimulatory molecules that drive T-cell activation and polarization. ${ }^{51}$ Thus, they effectively link the innate recognition of viruses to the generation of the appropriate type of adaptive immune response. DCs are a heterogeneous family, including langherans cells in the epidermis, interstitial DCs found in all peripheral tissues, myeloid DCs and plasmacytoid DCs found in the blood. Their heterogeneity resides at several levels, including anatomical location, phenotype and function. ${ }^{52} \mathrm{DCs}$ express a large repertoire of PRRs and, in response to signals from these receptors, they are activated and migrate to the T-cell area of regional lymph nodes where mDCs present virus-derived epitopes to $\mathrm{CD} 4^{+}$or $\mathrm{CD} 8^{+}$T cells. $^{53}$

DCs have a prominent role in promoting viral dissemination. Viruses, including HIV, have evolved 
different strategies to evade DC antiviral activity and to propagate and persist in DCs. HIV-1 replication in DCs is usually weakly productive, and the frequency of HIV-1infected DCs in vivo is much lower than that of HIV-1-infected $\mathrm{CD}^{+}{ }^{+} \mathrm{T}$ cells. ${ }^{54}$ However, DCs do not need to be productively infected to transmit the virus to CD4 $\mathrm{T}$ cells and to spread it in an infectious form. Analysis of conjugates between DCs and T cells revealed the recruitment of HIV and its receptors CD4, CCR5 and CXCR4 to DC-T cell junction, thus facilitating transmission of HIV during the formation of an infectious synapse in the absence of antigen-specific signaling. ${ }^{55}$ This process, known as 'trans-infection', takes place when part of the virus evades classical degradation pathways, being maintained in endosomal acidic compartments, thus retaining viral infectivity for long periods and promoting efficient HIV transfer to CD4 $\mathrm{T}$ cells. ${ }^{56,57}$ Trans-infection ability may be restricted to mDCs that display a greater ability to capture incoming virions, retain them in an infectious form in large vesicles within the cells, and transmit them to target CD4 ${ }^{+}$T cells, ${ }^{58,59}$ thus augmenting viral dissemination in the lymphoid tissues and significantly contributing to HIV disease progression. Therefore, the viral dissemination that mDCs potentially mediates in vivo is powerful, as viral transmission through trans-infection does not rely on antigen presentation, many $\mathrm{CD}^{+}{ }^{+} \mathrm{T}$ cells being exposed to $\mathrm{mDCs}$-exposing virus.

Recently, it has been suggested that HIV can exploit a preexisting exosome trans-dissemination pathway intrinsic to mDCs, thus allowing trans-infection of $\mathrm{CD}^{+}{ }^{+} \mathrm{T}$ cells. ${ }^{60,61}$ Exosomes are membrane vesicles of $30-100 \mathrm{~nm}$ in diameter and of endocytic origin, which are produced and secreted in vitro by living cells of diverse origin. They are involved in the stimulation of a specific immune response and they can transfer antigens from infected, tumoral, or antigen-presenting cells to $\mathrm{mDCs}$, increasing the number of $\mathrm{DCs}$ bearing a particular antigen, thus amplifying the initiation of primary adaptive immune response. ${ }^{62}$ Exosomes from DCs loaded with tumor-derived epitopes on MHC-I molecules are able to stimulate in vivo cytotoxic T lymphocyte-mediated anti-tumor responses, ${ }^{63}$ and to indirectly activate in vivo naïve $\mathrm{CD}^{+}$ $\mathrm{T}$ cells through the exchange of functional peptide-MHC complexes between DCs through a trans-dissemination mechanism. ${ }^{64} \mathrm{~A}$ recent study has shown that upon maturation, DCs are able to capture large amounts of HIV, HIV-gagVLP, or exosomes, resulting in localization within a CD81 ${ }^{+}$ compartment, and efficient transmission of captured particles to target $\mathrm{T}$ cells in an envelope glycoprotein-independent manner. ${ }^{65}$ This 'Trojan exosome pathway'60 used by mDCs that allows HIV to move between cells in the absence of fusion events could have a prominent role in promoting viral dissemination.

\section{HMGB1 is Pivotal During NK-DC Cross talk for DC Maturation and Th1 Polarization}

DC-dependent activation of NK cells. NK cells are involved in early viral control and by interacting with DCs they have a crucial role of producing pro-inflammatory cytokines and lysing infected cells. In addition, they can interact with $\mathrm{T}$ cells and DCs to shape the magnitude and quality of adaptive immune responses. ${ }^{66-68}$ Following tissue invasion by pathogens and subsequent initiation of inflammatory responses, NK cells migrate to lymphoid tissues in response to the chemokines IL- 8 and fractalkine (CX3CL1). In a mouse model, Lucas et al. ${ }^{69}$ showed that, in vivo, naive NK cells do not acquire effector function unless a priming step has occurred by contact with DCs in draining lymph nodes. The requirements for NK priming was independent of IL-12 and it included secretion of IFN- $\alpha$ by $\mathrm{TLR}^{+}$cells, which induced upregulation of IL-15R $\alpha$ and IL-15 expression by DCs, and trans-presentation of IL-15 by DCs to NK cells in the lymph node. NK cells are not fully activated during priming by DCs, as they do not spontaneously produce IFN- $\gamma$ or mediate cytotoxicity. Full activation of NK cells requires an additional contact with $\mathrm{mDCs}$. This results in mutual activation of previously primed NK cells and DC, ${ }^{70}$ and in the release of IFN- $\gamma$ by NK cells, thus contributing to antigen-driven T-cell activation. ${ }^{71}$ Blocking of IL-12 abolishes DC-induced IFN- $\gamma$ secretion by NK cells, whereas membrane-bound IL-15 on DCs is essential for NK cell proliferation and survival $^{72}$ (Figure 2).

NK-dependent maturation of DCs. NK/DC cross talk has an important role in the process of DC maturation. NK cells are involved in the positive selection of mature myeloid DCs that, after migration to secondary lymphoid compartments, induce priming of Th cells. ${ }^{73,74}$ Primed NK cells upregulate their cytotolytic function and they release cytokines such as TNF- $\alpha$ and IFN- $\gamma$, which in turn promote the maturation program of DCs that have captured the antigen. ${ }^{75-77}$ At this stage, NK cells acquire the capability to kill autologous iDC, an event that is dependent upon a process of NK cell activation involving the NKp30 receptor $^{78}$ and the TNFrelated apoptosis-inducing ligand (TRAIL)-DR4 pathway. ${ }^{22}$ NK cells would spare those DCs that after antigen uptake express high levels of HLA class I molecules, whereas they would kill those DCs (recruited in inflamed tissues) that failed to undergo a full maturation. This process involves inhibitory CD94/NKG2A receptors specific for the non-classical HLA-E molecules. ${ }^{74}$ mDCs are resistant to NK killing due to the upregulation of HLA class I expression including HLA-E. ${ }^{79}$ mDCs also upregulate an array of additional surface molecules including CCR7, CD80, CD86 and HLA class II, which allow their migration to lymph nodes and their optimal interaction with $T$ cells during their priming phase. Thus, during the early phases of inflammation, DC maturation is under the control of NK cells that have a major role in keeping in check the quality of DC undergoing maturation (Figure 2).

HMGB1 at the crossroad between innate and adaptive immunity. HMGB1 is expressed at the synapse between NK cells and DCs (Figure 3 ), and recent studies highlighted the pivotal role of this cytokine during NK-DC cross talk. Semino et al. ${ }^{80}$ showed that NK cells trigger immature DCs to polarize and secrete IL-18 at NK-DC synaptic cleft, thus instructing NK cells to release HMGB1, which promotes DC maturation and protects DCs from lysis. Interestingly, the ability of different NK cell subsets to induce DC maturation is unlinked to their phenotypic and cytolytic features but 
a

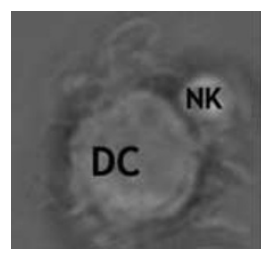

d

$0 \mathrm{sec}$

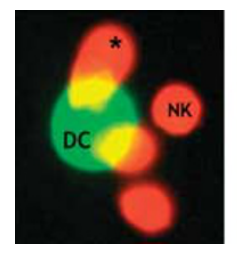

$100 \mathrm{sec}$

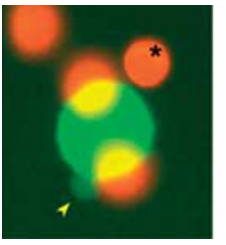

b

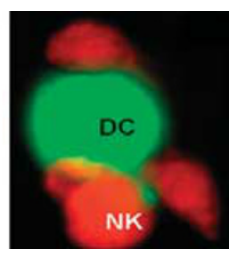

NK

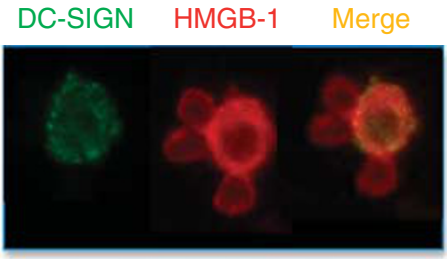

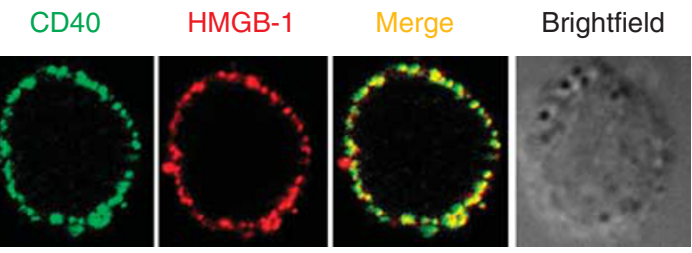

$60 \mathrm{sec}$

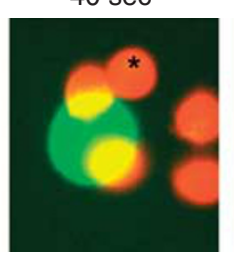

$120 \mathrm{sec}$

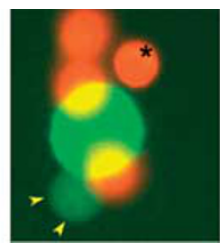

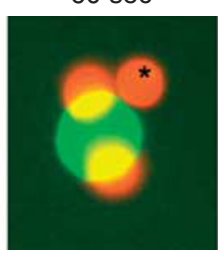

$140 \mathrm{sec}$

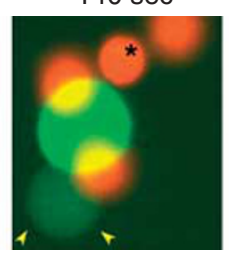

$80 \mathrm{sec}$

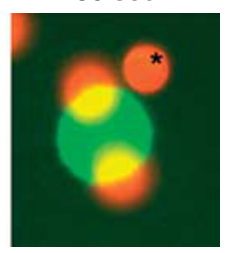

$160 \mathrm{sec}$

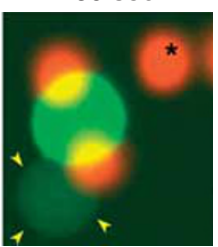

e
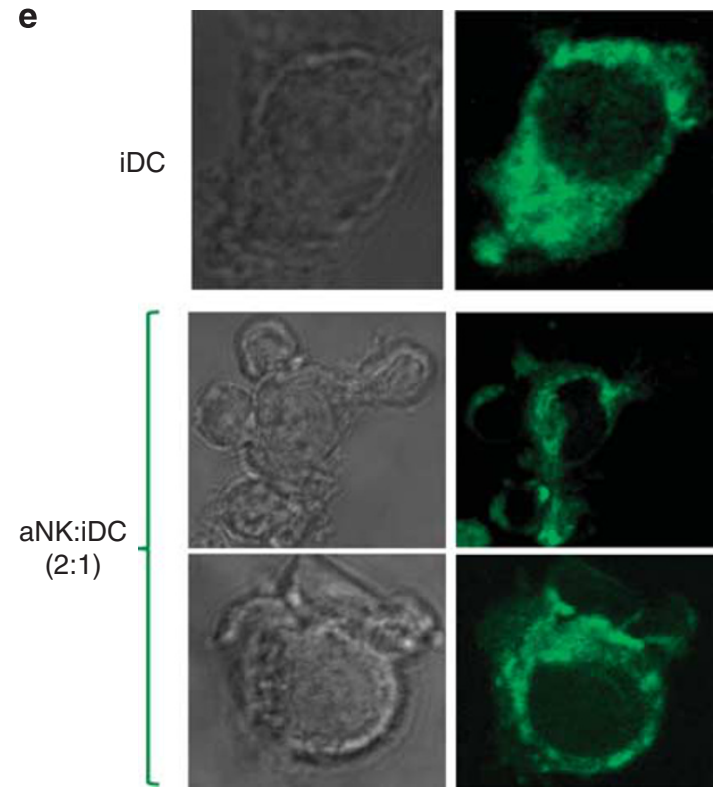

Brightfield

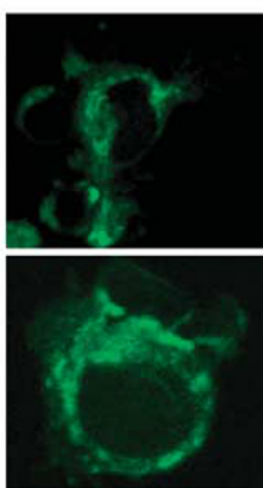

MitoTracker

Figure 3 Confocal microscopy analysis of NK-DC cross talk and HMGB1 expression. CD56 ${ }^{+}$NK cells sorted from PBMC of a healthy donor were cocultured for $24 \mathrm{~h}$ with iDCs generated from autologous monocytes (cultured for 5 days with IL-4 and GM-CSF). ${ }^{21}$ NK-DC cognate interaction was analyzed by confocal microscopy. (a) Stable NK-DC interaction. NK cells and DCs were stained with red and green Cell Tracker, respectively. (b) HMGB1 expression is detected with specific antibodies both in DCs, co-stained with DC-SIGN antibodies, and NK cells during NK-DC interaction. (c) Intracytoplasmatic HMGB1 expression in a DC costained with CD40-and HMGB1-specific antibodies. A brightfield picture of this DC is shown. (d) Sequential events from a video showing the killing of a DC following its contact with aNK cells (NK-DC ratio $5: 1$ ). NK cells and DCs were stained with red and green Cell Trackers, respectively. During the coculture, one NK cell interacted several times with the DC (pointed out with a star), leading to the killing of the DC. The DC died by apoptosis, as shown by the blebs (indicated with the yellow arrows). This editing process occurred very rapidly, within less than $1 \mathrm{~min}$ following the kiss of death by NK cells. ${ }^{22}$ (e) Mitochondria rearrangement at NK-DC synapse, detected with a green MitoTracker

correlates with the relocation of HMGB1 from the nucleus to the cytoplasm, which is strongly enhanced by engagement of the surface molecule NKp30. ${ }^{81}$ Moreover, in the presence of DC-derived cytokines, such as IL-12, a cooperation between NKp30 and DNAM-1 to induce NK cells to kill DCs, release TNF $-\alpha$ and promote DC maturation were evidenced. ${ }^{82}$ HMGB1 shows a nuclear localization in primary resting NK cells sorted from the blood, and the NK cell activation induces HMGB1 relocalization from the nucleus to the cytosol followed by extracellular release. ${ }^{21}$ During the cross talk between activated NK (aNK) cells and iDC, both NK cells and DCs express HMGB1 ${ }^{21}$ that appears essential for the upregulation of CD80, CD83 and CD86 maturation markers on DCs and for IL-12 production. The HMGB1 secreted during NK-DC cross talk is also essential for Th1 polarization of naïve CD4 T cells, and RAGE is required for HMGB1 effects on DCs. ${ }^{43,21}$ Moreover, the autocrine/paracrine release of $\mathrm{HMGB} 1$ is required for the upregulation on DCs of the CCR7 and CXCR4 chemokine receptors and their migration in response to the chemokines receptor ligands CCL19 and CXCL12, respectively, ${ }^{40}$ and RAGE has a nonredundant role in DC homing to lymph nodes, as shown in mice by noninvasive imaging by magnetic resonance. ${ }^{41}$ Overall, HMGB1-RAGE pathway is activated in DCs that are committed to maturation in peripheral tissues, and it controls the expression of chemokine receptors in DCs that acquire the ability to reach secondary lymphoid organs where they initiate the clonal expansion of Ag-specific $\mathrm{T}$ cells. The disruption of HMGB1-RAGE pathway by specific inhibitors ${ }^{43,21}$ or the genetic deletion of RAGE ${ }^{41}$ interrupts this circuit, possibly limiting the initiation of $\mathrm{T}$-cell adaptive response.

\section{HMGB1 and HIV Dissemination and Persistence in DCs}

HMGB1 modulates HIV replication in myeloid cells. Intracellular HMGB1 was reported to affect HIV-1 longterm-repeat (LTR)-directed transcription in a promoter- and cell-specific manner. For example, HMGB1-dependent repression of HIV genes was observed in epithelial cells, Hela cells and monocytic cells, but not in unstimulated Jurkat 
(1)

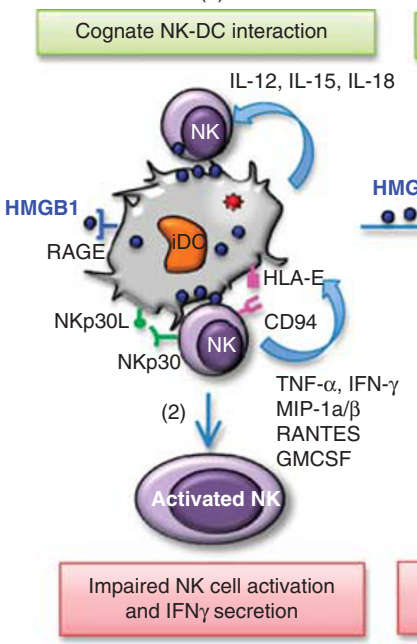

(3)

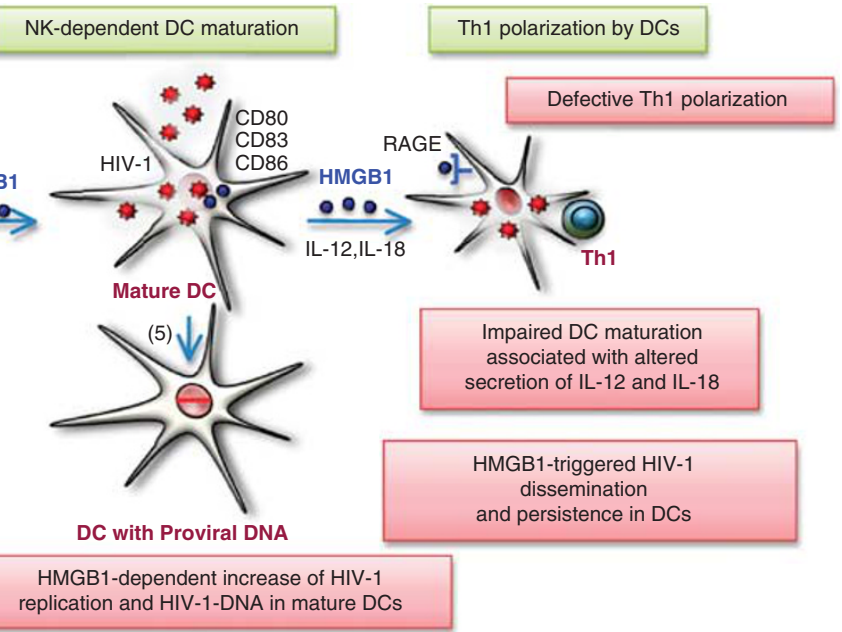

(4)

Th1 polarization by DC

Figure 4 Impact of HIV-1 infection on HMGB1-dependent DC maturation and Th1 polarization. Cognate interaction between resting NK cells and DCs is required for DC maturation (1). This bidirectional cross talk that involves NK receptors NKp30 and CD94/NKG2A, leads both to NK cell activation (2) and DC maturation (3), through the release of cytokines by both cells. In addition, HMGB1 produced both by NK cells and DCs, has a pivotal in NK-dependent DC maturation. During HIV-1 infection, NK-DC cross talk is impaired. NK cell activation is altered and HMGB1-dependent DC maturation is incomplete. Cognate interaction of infected iDCs with NK cells leads to their phenotypic maturation, as evidenced by the expression of maturation markers, including CD80, CD83 or CD86 (3), but not to their functional maturation shown by the inability of DCs to polarize a Th1 response in naïve T cells (4). This functional impairment is associated with the absence of release by DCs of IL-12 and IL-18 required for Th1 induction. Moreover, cognate NK-DC interaction leads to the increase of HIV-1 replication in infected DCs and to the accumulation of DCs with proviral DNA (5). The triggering of HIV-1 replication in DCs is mediated by HMGB1. Thus, HMGB1 contributes to HIV-1 dissemination and persistence

cells. This inhibitory effect of HMGB1 was caused by repression of LTR-mediated transcription. ${ }^{83}$ Extracellular HMGB1 also showed a dichotomic effect in different cell types. Addition of HMGB1 to primary monocytes with active HIV-1 infection was reported to suppress viral replication, associated $^{19}$ or not associated ${ }^{20}$ to HMGB1-mediated increased release of $\beta$-chemokines (RANTES, MIP- $1 \alpha$ and MIP-1 $\beta$ ), strong inhibitors of HIV entry. In contrast, extracellular HMGB1 increased HIV-1 replication in the chronically infected monocytic cell line $\mathrm{U} 1,{ }^{19}$ a process that did not require de novo protein synthesis. ${ }^{84} \mathrm{HIV}-1$ induction relied on HMGB1-RAGE interaction, involved p38, ERK and $\mathrm{NF}-\kappa \mathrm{B}$ pathway, and stimulated the release of $\mathrm{TNF}-\alpha^{84}$ Interestingly, HMGB1 could reactivate ex-vivo quiescent HIV-1 from latently infected PBMC collected in aviremic HIV-infected patients. ${ }^{84}$ Thus, HMGB1 may reduce viral replication in acute infection by inducing inhibitors of viral entry, but it may trigger viral replication in latently infected cells, including in cells from HIV-infected patients.

NK-DC cross talk contributes to HIV replication through HMGB1. The mechanisms involved in NK-DC interaction during viral infections are poorly understood. It was recently reported in murine CMV (MCMV) infection that MCMVinfected DCs were capable of activating syngeneic NK cells in vitro and also capable of enhancing NK-dependent clearance in vivo, ${ }^{85}$ demonstrating the crucial role of NK-DC cross talk in controlling viral replication. In HIV infection, NK-DC interaction was found defective in viremic HIV-1-infected patients, characterized by abnormalities in the process of reciprocal NK-DC activation and maturation. ${ }^{86}$ Recently, we investigated the impact of HIV-1 on NKdependent maturation and function of iDCs in an ex-vivo model of cross talk between purified primary NK cells and monocytes-derived iDCs.

We discovered that maturation of HIV-1-infected DCs required aNK to occur and this process involved HMGB1. Blocking HMGB1 with specific antibodies or glycyrrhizin, a specific inhibitor of HMGB1, impaired maturation of infected DCs. However, the cross talk between HIV-1-infected DCs and aNK cells was functionally defective, as demonstrated by the strong impairment of DCs to induce Th1 polarization of naïve CD4 $T$ cells. This was associated with the defective production of IL-12 and IL-18 by infected DCs, known to trigger the adaptive response. ${ }^{21}$ Moreover, the interaction between aNK and HIV-1-infected DCs resulted in a dramatic increase in viral replication and proviral DNA expression in DCs. This process was mainly triggered by HMGB1, released both by NK cells and DCs, and blocking HMGB1 strongly inhibited HIV replication in both isolated infected DCs and DCs cocultured with aNK cells ${ }^{21}$ (Figure 4). Thus, these findings provide evidence for the crucial role of NK-DC cross talk in promoting viral dissemination, and challenge the question of the in vivo involvement of HMGB1 in the triggering of HIV-1 replication and replenishment of viral reservoirs in AIDS.

NK-DC cross talk and HMGB-dependent HIV persistence in DCs. The NK cell-mediated editing process of DCs, which is required to keep in check the quality of DCs prone to mature and further present the antigen to $T$ cells, is compromised during HIV infection. Indeed, NK cells from viremic patients show a decreased ability to kill immature DCs. ${ }^{87}$ The defect is associated with an increase in the proportion of $\mathrm{CD}^{-} 6^{-} \mathrm{NK}$ cells with impaired NKp30 function. ${ }^{86}$ In addition, increased production of IL-10 during 
(1)

Cognate aNK-iDC interaction

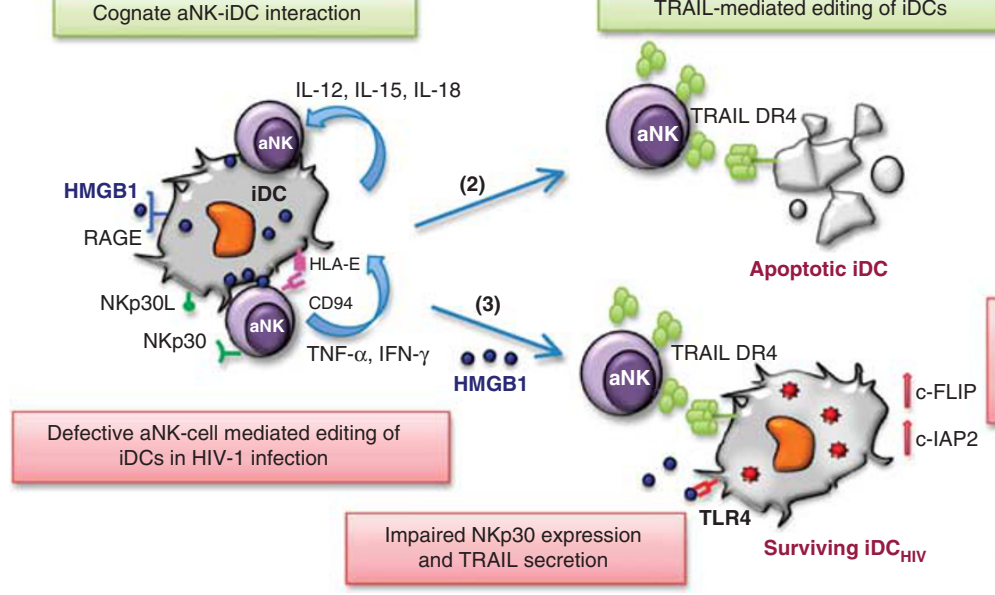

(4)

HMGB1-mediated resistance of infected

iDCs to TRAIL-induced apoptosis

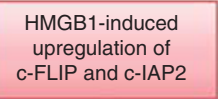

Figure 5 Impact of HIV-1 infection on NK cell-mediated editing of iDCs. NK cells are involved in the positive selection of DCs through the editing process, which is required to keep in check the quality of DCs prone to mature and further present the antigens to T cells. Thus, cognate interaction between aNK and iDC may lead to the killing of iDC (1). NK cell-dependent killing of iDCs involves the activating NKp30 receptor (1) and the DR4/TRAIL death receptor pathway (2). HIV-1 infection induces a defective editing process. NK cells show a decreased ability to kill infected DCs associated with impaired NKp30 expression and TRAIL secretion (3), and infected DCs become resistant to NK-mediated killing due to the upregulation of two anti-apoptotic molecules, c-FLIP and c-IAP2 (4). HMGB1 induces these two potent inhibitors of apoptosis in infected DCs, thus making them resistant to NK killing

HIV-1 infection can protect immature DCs from NK cellmediated lysis, resulting in accumulation of partially mature, poorly immunogenic DCs in the lymph nodes of infected individuals. ${ }^{88}$ In an ex-vivo model of NK-DC cross talk, we showed that HIV-1-infected DCs become resistant to NK cellmediated lysis due to an upregulation in DCs of two apoptosis inhibitors, cellular FLICE-inhibitory protein (cFLIP) and cellular inhibitor of apoptosis protein 2 (c-IAP2). ${ }^{22}$ The expression of these inhibitors was upregulated by HMGB1, released by aNK cells at NK-DC synapse, and they protected HIV-1-infected DCs from TRAIL-dependent apoptosis. ${ }^{22}$ Blocking HMGB1 with specific antibodies restored the susceptibility of infected DCs to NK killing, and similar effect was observed knocking down c-FLIP or c-IAP2 by siRNA ${ }^{22}$ (Figure 5). Overall, these findings suggest that impaired NK-DC cross talk during HIV1 infection is a consequence of bidirectional alteration of both DC and NK cell functions, and they reveal the pivotal role of HMGB1 in HIV-1 persistence in DCs.

\section{HMGB1, Immune Activation and HIV-1 Disease Progression}

Extracellular HMGB1 is an important component contributing to tissue injury in acute and chronic inflammatory conditions. HMGB1 and its receptors RAGE, TLR2 and TLR4 have been implicated in mechanisms of many diseases, including cancer, sepsis, atherosclerosis, stroke, rheumatoid arthritis and many other inflammatory conditions. ${ }^{89}$ Plasma levels of HMGB1 are elevated during the course of HIV-1 infection ${ }^{17}$ and positively associated with high viral load. ${ }^{90}$ HMGB1 can be passively released by virus-infected cells including primary CD4 T cells infected with HIV-1, and this was associated with both necrotic and apoptotic cell death. ${ }^{91}$ HMGB1 can also be released by non-infected apoptotic CD4 $\mathrm{T}$ cells that die through a bystander killing process, which is mainly induced by extracellular HIV-1-encoded proteins and by HIV-1associated chronic immune activation. ${ }^{46}$ Increased circulating HMGB1 levels detected in progressive HIV-1 infection, combined with microbial products and TLR ligands, may contribute to gut inflammation and subsequent microbial translocation, suggested to have an important role in HIV pathogenesis. $^{92}$ Microbial translocation is the leaking of normally friendly commensal bacteria from the gut - where they are usually contained - into the systemic circulation. Brenchley et al. ${ }^{92}$ proposed that this phenomenon contributes to immune activation in patients with HIV, and thus has a causative role in the progression of the disease. Markers of microbial translocation found in the bloodstream include LPS and bacterial DNA, and the level of circulating LPS in the first year of chronic HIV infection is a strong predictor of disease progression independent of CD4 T-cell count and HIV viraemia. $^{93}$

The possible link between circulating LPS and HMGB1 levels in inflammatory conditions is suggested by following recent observations: (1) priming of macrophages with LPS induces the processing and releasing of HMGB1 in addition to $\mathrm{IL}-1 \beta$, IL-18 and TNF- $\alpha$, which requires the inflammasome components ASC, caspase 1 and NALP3; ${ }^{28}$ (2) conversely, NALP3 silencing has a protective effect in a murine model of liver ischemia-reperfusion injury, associated with decreased production of HMGB1, IL-1 $\beta$, IL-18, TNF- $\alpha$ and IL-6; ${ }^{94}$ (3) the resistance of caspase-1-deficient mice to LPS correlates with reduced serum HMGB1 levels. ${ }^{28}$ (4) HMGB1 forms highly inflammatory complexes with LPS, and signals through the TLR4; ${ }^{95}$ (5) an association of elevated circulating levels of LPS and high viral load was reported in HIV-infected patients. ${ }^{90}$ Thus, HMGB1-LPS complexes may be important in perpetuating inflammatory amplification loops in HIV disease. 


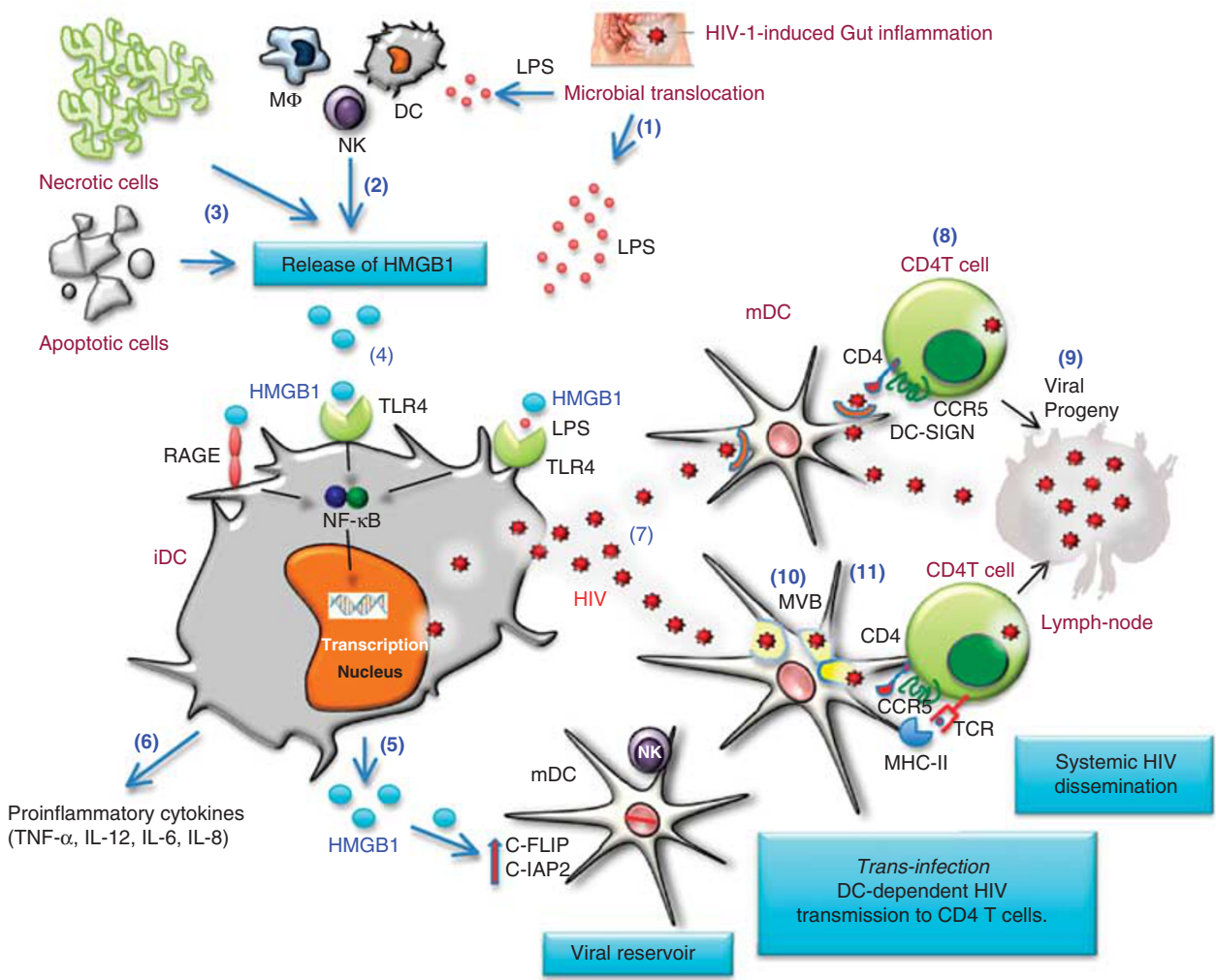

Figure 6 Proposed contribution of HMGB1 to HIV persistence and dissemination. HIV disease progression is characterized by gut inflammation and consequently microbial translocation leading to the release of LPS in the bloodstream (1). Circulating LPS may induce active release of HMGB1 by innate cells, including macrophages and DCs (2). Necrotic and apoptotic cells that accumulate during chronic HIV infection may also be a constant source of HMGB1 (3). HMGB1 activates DCs by signaling through the receptor RAGE or TLR4 if cooperate with TLR4 ligand LPS, thus triggering NF- $\kappa B$ activation (4). This results in the release of HMGB1 (5) and proinflammatory cytokines (6), and the triggering of HIV replication in MDCs (7). Trans-infection of HIV from mDCs to CD4 T cells involves HIV capture by DC-SIGN followed by its recruitment at the site of T-cell interaction (8). This infectious synapse will lead to the productive infection of CD4 T cells (9). Trans-infection of HIV can also be mediated by exocytosis of the HIV-1 particles captured by DCs. After endocytosis, the captured HIV-1 particles are targeted to a multi-vesicular endosomal body (MVB) in DCs (10). Although some of the MVB-localized virus fraction is targeted to the lysosome and degraded to be further presented to TCR in the context of MHC molecules, fusion of MVB with the plasma membrane results in the release of virus particles along with exosomes (11). Virus produced by infected CD4 T cells, DCs and macrophages spread the infection to the draining lymph nodes and other lymphoid tissue

Thus, HMGB1 by itself, or combined to LPS or other TLR ligand or cytokines, may induce a self-perpetuating cycle by contributing to immune activation that creates new T-cell targets for viral infection and subsequent increased rate of cell death and release of HMGB1, but also by stimulating HIV replication and viral persistence in DCs. This vicious circle may facilitate HIV disease progression and contribute to AIDS pathogenesis (Figure 6).

\section{Conclusions and Major Open Questions}

HMGB1 is an endogenous danger signal that can be released into the extracellular milieu during states of cellular stress or damage, and that is also actively produced by innate effectors such as NK cells subsequently involved in promoting adaptive immunity. HMGB1 has a pivotal role during NK-DC cross talk but, in the context of a chronic viral infection such as that induced by HIV-1, it triggers viral replication in DCs and blocks NK-mediated killing of infected DCs, thus contributing to viral persistence. Increased circulating HMGB1 levels are detected in progressive HIV-1-infected individuals and, in combination with microbial products and TLR ligands, it may also contribute to gut inflammation and subsequently increase microbial translocation and chronic immune activation, a hallmark of HIV-1 disease progression. In order to get a better understanding on the role of HMGB1 in HIV disease and to develop interventions aimed at enhancing immunity to HIV-1, several major questions need to be addressed.

\section{Conflict of Interest}

The authors declare no conflict of interest.

Acknowledgements. This work was supported by research funding from Sidaction to MLG. MTM was supported by a PhD grant from MESR (Ministère de l'Enseignement Supérieur et de la Recherche), and HS by a postdoctoral fellowship from Sidaction and from ANRS (National Agency for AIDS Research).

1. Thomas JO, Travers AA. HMG1 and 2, and related 'architectural' DNA-binding proteins Trends Biochem Sci 2001; 26: 167-174.

2. Ciubotaru M, Schatz DG. Synapsis of recombination signal sequences located in cis and DNA underwinding in V(D)J recombination. Mol Cell Biol 2004; 24: 8727-8744.

3. Stros M, Ozaki T, Bacikova A, Kageyama H, Nakagawara A. HMGB1 and HMGB2 cellspecifically down-regulate the p53-and p73-dependent sequence-specific transactivation from the human Bax gene promoter. J Biol Chem 2002; 277: 7157-7164. 
4. Zong WX, Ditsworth D, Bauer DE, Wang ZQ, Thompson CB. Alkylating DNA damage stimulates a regulated form of necrotic cell death. Genes Dev 2004; 18: 1272-1282.

5. Stros M, Muselikova-Polanska E, Pospisilova S, Strauss F. High-affinity binding of tumorsuppressor protein p53 and HMGB1 to hemicatenated DNA loops. Biochemistry 2004; 43: 7215-7225.

6. Knapp S, Muller S, Digilio G, Bonaldi T, Bianchi ME, Musco G. The long acidic tail of high mobility group box 1 (HMGB1) protein forms an extended and flexible structure that interacts with specific residues within and between the HMG boxes. Biochemistry 2004; 43 11992-11997.

7. Tang DL, Kang R, Livesey KM, Cheh CW, Farkas A, Loughran $P$ et al. Endogenous HMGB1 regulates autophagy. J Cell Biol 2010; 190: 881-892.

8. Liu L, Yang M, Kang R, Wang Z, Zhao Y, Yu Y et al. HMGB1-induced autophagy promotes chemotherapy resistance in leukemia cells. Leukemia 2011; 25: 23-31.

9. Wang HC, Bloom O, Zhang MH, Vishnubhakat JM, Ombrellino M, Che JT et al. HMG-1 as a late mediator of endotoxin lethality in mice. Science 1999; 285: 248-251.

10. Oppenheim JJ, Tewary P, de la Rosa G, Yang D. Alarmins initiate host Defense In: Shurin MR, Smolkin YS (eds) Immune-Mediated Diseases: from Theory to Therapy 2007, pp 185-194.

11. Yang D, Chen $\mathrm{Q}$, Yang $\mathrm{H}$, Tracey KJ, Bustin M, Oppenheim JJ. High mobility group box-1 protein induces the migration and activation of human dendritic cells and acts as an alarmin. J Leukoc Biol 2007; 81: 59-66.

12. Bianchi ME. DAMPs, PAMPs and alarmins: all we need to know about danger. J Leukoc Biol 2007; 81: 1-5.

13. Yang $\mathrm{H}$, Yuan $\mathrm{RQ}$, Wang $\mathrm{HC}$, Ochani M, Tracey KJ. Role of HMGB1 in apoptosis-mediated sepsis lethality. Inflamm Res 2007; 56: S88-S89.

14. Pisetsky DS, Erlandsson-Harris $H$, Andersson U. High-mobility group box protein 1 (HMGB1): an alarmin mediating the pathogenesis of rheumatic disease. Arthritis Res Ther 2008; 10: 209.

15. Abdulahad DA, Westra J, Limburg PC, Kallenberg CGM, Bijl M. HMGB1 in systemic lupus erythematosus: its role in cutaneous lesions development. Autoimmun Rev 2010; 9 661-665.

16. Wang HC, Ward MF, Fan XG, Sama AE, Li W. Potential role of high mobility group box 1 in viral infectious diseases. Viral Immunol 2006; 19: 3-9.

17. Nowak $P$, Barqasho $B$, Sonnerborg $A$. Elevated plasma levels of high mobility group box protein 1 in patients with HIV-1 infection. AIDS 2007; 21: 869-871

18. Ivanov S, Dragoi AM, Wang X, Dallacosta C, Louten J, Musco G et al. A novel role for HMGB1 in TLR9-mediated inflammatory responses to CpG-DNA. Blood 2007; 110: 1970-1981

19. Nowak P, Barqasho B, Treutiger CJ, Harris HE, Tracey KJ, Andersson J et al. HMGB1 activates replication of latent HIV-1 in a monocytic cell-line, but inhibits HIV-1 replication in primary macrophages. Cytokine 2006; 34: 17-23.

20. Cassetta L, Fortunato O, Adduce L, Rizzi C, Hering J, Rovere-Querini $P$ et al Extracellular high mobility group box-1 inhibits R5 and X4 HIV-1 strains replication in mononuclear phagocytes without induction of chemokines and cytokines. AIDS 2009; 23 : 567-577.

21. Saidi H, Melki MT, Gougeon ML. HMGB1-dependent triggering of HIV-1 replication and persistence in dendritic cells as a consequence of NK-DC cross-talk. Plos One 2008; 3 . e3601.

22. Melki MT, Saidi H, Dufour A, Olivo-Marin JC, Gougeon ML. Escape of HIV-1-infected dendritic cells from TRAIL-mediated NK cell cytotoxicity during NK-DC cross-talk-a pivotal role of HMGB1. Plos Pathog 2010; 6: e1000862.

23. Medzhitov R. Recognition of microorganisms and activation of the immune response. Nature 2007; 449: 819-826.

24. Yanai H, Ban T, Wang ZC, Choi MK, Kawamura T, Negishi H et al. HMGB proteins function as universal sentinels for nucleic-acid-mediated innate immune responses. Nature 2009; 462: U99-U110.

25. Tian J, Avalos AM, Mao SY, Chen B, Senthil K, Wu H et al. Toll-like receptor 9-dependent activation by DNA-containing immune complexes is mediated by HMGB1 and RAGE. Nat Immunol 2007; 8: 487-496.

26. Scaffidi $P$, Misteli T, Bianchi ME. Release of chromatin protein HMGB1 by necrotic cells triggers inflammation. Nature 2002; 418: 191-195.

27. Raucci A, Palumbo R, Bianchi ME. HMGB1: a signal of necrosis. Autoimmunity 2007; 40 285-289.

28. Lamkanfi M, Sarkar A, Walle LV, Vitari AC, Amer AO, Wewers MD et al. Inflammasomedependent release of the alarmin HMGB1 in endotoxemia. Nat Immunol 2010; 185 4385-4392.

29. Dumitriu IE, Baruah P, Manfredi AA, Bianchi ME, Rovere-Querini P. HMGB1: guiding immunity from within. Trends Immunol 2005; 26: 381-387.

30. Rendon-Mitchell B, Ochani M, Li JH, Hang JL, Wang H, Yang $\mathrm{H}$ et al. IFN-gamma induces high mobility group box 1 protein release partly through a TNF-dependent mechanism. J Immunol 2003; 170: 3890-3897.

31. Gardella S, Andrei C, Ferrera D, Lotti LV, Torrisi MR, Bianchi ME et al. The nuclear protein HMGB1 is secreted by monocytes via a non-classical, vesicle-mediated secretory pathway. Embo Rep 2002; 3: 995-1001.

32. Hoppe G, Talcott KE, Bhattacharya SK, Crabb JW, Sears JE. Molecular basis for the redox control of nuclear transport of the structural chromatin protein Hmgb1. Exp Cell Res 2006; 312: $3526-3538$.
33. Youn JH, Shin JS. Nucleocytoplasmic shuttling of HMGB1 is regulated by phosphorylation that redirects it toward secretion. J Immunol 2006; 177: 7889-7897.

34. Ito I, Fukazawa J, Yoshida M. Post-translational methylation of high mobility group box 1 (HMGB1) causes its cytoplasmic localization in neutrophils. J Biol Chem 2007; 282: 16336-16344.

35. Bonaldi T, Talamo F, Scaffidi P, Ferrera D, Porto A, Bachi A et al. Monocytic cells hyperacetylate chromatin protein HMGB1 to redirect it towards secretion. Embo J2003; 22: 5551-5560.

36. Oh YJ, Youn JH, Ji Y, Lee SE, Lim KJ, Choi JE et al. HMGB1 is phosphorylated by classical protein kinase $C$ and is secreted by a calcium-dependent mechanism. $J$ Immunol 2009; 182: $5800-5809$.

37. Urbonaviciute V, Meister S, Furnrohr BG, Frey B, Guckel E, Schett G et al. Oxidation of the alarmin high-mobility group box 1 protein (HMGB1) during apoptosis. Autoimmunity 2009; 42: 305-307.

38. Kazama H, Ricci JE, Herndon JM, Hoppe G, Green DR, Ferguson TA. Induction of immunological tolerance by apoptotic cells requires caspase-dependent oxidation of high-mobility group box-1 protein. Immunity 2008; 29: 21-32.

39. Rubartelli A, Lotze MT. Inside, outside, upside down: damage-associated molecularpattern molecules (DAMPs) and redox. Trends Immunol 2007; 28: 429-436.

40. Dumitriu IE, Bianchi ME, Bacci M, Manfredi AA, Rovere-Querini $P$. The secretion of HMGB1 is required for the migration of maturing dendritic cells. J Leukoc Biol 2007; 81: 84-91.

41. Manfredi AA, Capobianco A, Esposito A, De Cobelli F, Canu T, Monno A et al. Maturing dendritic cells depend on RAGE for in vivo homing to lymph nodes. J Immunol 2008; 180: 2270-2275.

42. Messmer D, Yang H, Telusma G, Knoll F, Li JH, Messmer B et al. High mobility group box protein 1: An endogenous signal for dendritic cell maturation and Th1 polarization. J Immunol 2004; 173: 307-313.

43. Dumitriu IE, Baruah P, Valentinis B, Voll RE, Herrmann M, Nawroth PP et al. Release of high mobility group box 1 by dendritic cells controls $T$ cell activation via the receptor for advanced glycation end products. J Immunol 2005; 174: 7506-7515.

44. Campana L, Bosurgi L, Bianchi ME, Manfredi AA, Rovere-Querini P. Requirement of HMGB1 for stromal cell-derived factor-1/CXCL12-dependent migration of macrophages and dendritic cells. J Leukoc Biol 2009; 86: 609-615.

45. Chen GY, Tang J, Zheng P, Liu Y. CD24 and siglec-10 selectively repress tissue damageinduced immune responses. Science 2009; 323: 1722-1725.

46. Gougeon ML. Apoptosis as an HIV strategy to escape immune attack. Nat Rev Immuno 2003; 3: 392-404.

47. Miller CJ, Li QS, Abel K, Kim EY, Ma ZM, Wietgrefe S et al. Propagation and dissemination of infection after vaginal transmission of simian immunodeficiency virus. J Virol 2005; 79: 9217-9227.

48. Zhang ZQ, Schuler T, Zupancic M, Wietgrefe S, Staskus KA, Reimann KA et al. Sexual transmission and propagation of SIV and HIV in resting and activated CD4(+) T cells. Science 1999; 286: 1353-1357.

49. Haase AT. Targeting early infection to prevent HIV-1 mucosal transmission. Nature 2010; 464: 217-223.

50. Hu JJ, Gardner MB, Miller CJ. Simian immunodeficiency virus rapidly penetrates the cervicovaginal mucosa after intravaginal inoculation and infects intraepithelial dendritic cells. J Virol 2000; 74: 6087-6095.

51. Lanzavecchia A, Sallusto $F$. The instructive role of dendritic cells on $T$ cell responses: lineages, plasticity and kinetics. Curr Opin Immunol 2001; 13: 291-298.

52. Lambotin M, Raghuraman S, Stoll-Keller F, Baumert TF, Barth H. A look behind closed doors: interaction of persistent viruses with dendritic cells. Nat Rev Microbiol 2010; 8 : 350-360.

53. Steinman RM, Banchereau J. Taking dendritic cells into medicine. Nature 2007; 449 . $419-426$

54. Mcllroy D, Autran B, Cheynier R, Wainhobson S, Clauvel JP, Oksenhendler E et al. Infection frequency of dendritic cells and CD4(+) T-lymphocytes in spleens of human immunodeficiency virus-positive patients. J Virol 1995; 69: 4737-4745

55. McDonald D, Wu L, Bohks SM, KewalRamani VN, Unutmaz D, Hope TJ. Recruitment of HIV and its receptors to dendritic cell-T cell junctions. Science 2003; 300: $1295-1297$.

56. Geijtenbeek TBH, Kwon DS, Torensma R, van Vliet SJ, van Duijnhoven GCF, Middel J et al. DC-SIGN, a dendritic cell-specific HIV-1-binding protein that enhances trans-infection of T cells. Cell 2000; 100: 587-597.

57. Kwon DS, Gregorio G, Bitton N, Hendrickson WA, Littman DR. DC-SIGN-mediated internalization of HIV is required for trans-enhancement of T cell infection. Immunity 2002; 16: $135-144$

58. Izquierdo-Useros N, Blanco J, Erkizia I, Fernandez-Figueras MT, Borras FE, Naranjo-Gomez $\mathrm{M}$ et al. Maturation of blood-derived dendritic cells enhances human immunodeficiency virus type 1 capture and transmission. $J$ Virol 2007; 81: 7559-7570.

59. Wang JH, Janas AM, Olsonj WJ, Wu L. Functionally distinct transmission of human immunodeficiency virus type mediated by immature and mature dendritic cells. $J$ Virol 2007; 81: 8933-8943.

60. Gould SJ, Booth AM, Hildreth JEK. The Trojan exosome hypothesis. Proc Natl Acad Sci USA 2003; 100: 10592-10597. 
61. Izquierdo-Useros N, Naranjo-Gomez M, Erkizia I, Puertas MC, Borras FE, Blanco J et al. HIV and mature dendritic cells: Trojan exosomes riding the Trojan horse? Plos Pathog 2010; 6: e1000740.

62. Thery C, Zitvogel L, Amigorena S. Exosomes: composition, biogenesis and function Nat Rev Immunol 2002; 2: 569-579.

63. Zitvogel L, Regnault A, Lozier A, Wolfers J, Flament C, Tenza D et al. Eradication of established murine tumors using a novel cell-free vaccine: dendritic cell-derived exosomes. Nat Med 1998; 4: 594-600.

64. Thery C, Duban L, Segura E, Veron P, Lantz O, Amigorena S. Indirect activation of naive CD4(+) T cells by dendritic cell-derived exosomes. Nat Immunol 2002; 3 : $1156-1162$.

65. Izquierdo-Useros N, Naranjo-Gomez M, Archer J, Hatch SC, Erkizia I, Blanco J et al. Capture and transfer of HIV-1 particles by mature dendritic cells converges with the exosome-dissemination pathway. Blood 2009; 113: 2732-2741.

66. Fernandez NC, Lozier A, Flament C, Ricciardi-Castagnoli P, Bellet D, Suter M et al. Dendritic cells directly trigger NK cell functions: cross-talk relevant in innate anti-tumor immune responses in vivo. Nat Med 1999; 5: 405-411.

67. Mailliard RB, Son YI, Redlinger R, Coates PT, Giermasz A, Morel PA et al. Dendritic cells mediate NK cell help for Th1 and CTL responses: two-signal requirement for the induction of NK cell helper function. J Immunol 2003; 171: 2366-2373.

68. Degli-Esposti MA, Smyth MJ. Close encounters of different kinds: dendritic cells and NK cells take centre stage. Nat Rev Immunol 2005; 5: 112-124.

69. Lucas M, Schachterle W, Oberle K, Aichele P, Diefenbach A. Dendritic cells prime natural killer cells by trans-presenting interleukin 15 . Immunity 2007; 26: 503-517.

70. Martin-Fontecha A, Thomsen LL, Brett S, Gerard C, Lipp M, Lanzavecchia A et al. Induced recruitment of NK cells to lymph nodes provides IFN-gamma for $T(H) 1$ priming. Nat Immunol 2004; 5: 1260-1265.

71. Bajenoff M, Breart B, Huang AYC, Qi H, Cazareth J, Braud VM et al. Natural killer cell behavior in lymph nodes revealed by static and real-time imaging. J Exp Med 2006; 203: 619-631.

72. Ferlazzo G, Pack M, Thomas D, Paludan C, Schmid D, Strowig T et al. Distinct roles of IL-12 and IL-15 in human natural killer cell activation by dendritic cells from secondary lymphoid organs. Proc Natl Acad Sci USA 2004; 101: 16606-16611.

73. Moretta A. Natural killer cells and dendritic cells: rendezvous in abused tissues. Nat Rev Immunol 2002; 2: 957-964.

74. Della Chiesa M, Vitale M, Carlomagno S, Ferlazzo G, Moretta L, Moretta A. The natural killer cell-mediated killing of autologous dendritic cells is confined to a cell subset expressing CD94/NKG2A, but lacking inhibitory killer Ig-like receptors. Eur J Immunol 2003; 33: 1657

75. Vitale M, Della Chiesa M, Carlomagno S, Pende D, Arico M, Moretta L et al. NK-dependent DC maturation is mediated by TNF alpha and IFN gamma released upon engagement of the NKp30 triggering receptor. Blood 2005; 106: 566-571.

76. Sivori S, Falco M, Della Chiesa M, Carlomagno S, Vitale M, Moretta $L$ et al. CpG and double-stranded RNA trigger human NK cells by Toll-like receptors: induction of cytokine release and cytotoxicity against tumors and dendritic cells. Proc Natl Acad Sci USA 2004 101: 10116-10121.

77. Piccioli D, Sbrana S, Melandri E, Valiante NM. Contact-dependent stimulation and inhibition of dendritic cells by natural killer cells. J Exp Med 2002; 195: 335-341.

78. Ferlazzo G, Tsang ML, Moretta L, Melioli G, Steinman RM, Munz C. Human dendritic cells activate resting natural killer (NK) cells and are recognized via the NKp30 receptor by activated NK cells. J Exp Med 2002; 195: 343-351.

\section{Relevant references}

Wang HC, Bloom O, Zhang MH, Vishnubhakat JM, Ombrellino M, Che JT et al. HMG-1 as a late mediator of endotoxin lethality in mice. Science 1999; 285: 248-251. First demontration of the in vivo involvement and lethality of HMG-1 in a murine model of endotoxemia.

Yanai H, Ban T, Wang ZC, Choi MK, Kawamura T, Negishi $\mathrm{H}$ et al. HMGB proteins function as universal sentinels for nucleic-acid-mediated innate immune responses. Nature 2009; 462: U99-U110. Elegant study showing that HMGB proteins function as nucleic-acid-sensing systems, their absence severely impairing nucleic-acid-mediated TLRs activation and induction of innate responses.

Scaffidi P, Misteli T, Bianchi ME. Release of chromatin protein HMGB1 by necrotic cells triggers inflammation. Nature 2002; 418: 191-195. Cells undergoing necrosis release HMGB1 that signals the demise of a cell to its neighbours. In contrast, cells undergoing apoptosis are programmed to withhold this signal, thus not triggering inflammation.

Dumitriu IE, Bianchi ME, Bacci M, Manfredi AA, Rovere-Querini P. The secretion of HMGB is required for the migration of maturing dendritic cells. J Leu Biol 2007; 81 84-91. The migratory functions of human DCs require the autocrine/paracrine release of HMGB1, which upregulates chemokine receptors and induces their response to chemokine-receptor ligands in a RAGE-dependent manner.

Semino C, Angelini G, Poggi A, Rubartelli A. NK/iDC interaction results in IL-18 secretion by DCs at the synaptic cleft followed by NK cell activation and release of the DC maturation factor HMGB1. Blood 2005; 106: 609-616. First demonstration of the essential role of HMGB1 in NK-DC crosstalk. IL-18 produced by DCs activates NK cells to release HMGB1, which induces DC maturation, thus favoring the onset of the adaptive immune response.
79. Moretta A. The dialogue between human natural killer cells and dendritic cells. Curr Opin Immunol 2005; 17: 306-311.

80. Semino C, Angelini G, Poggi A, Rubartelli A. NK/iDC interaction results in IL-18 secretion by DCs at the synaptic cleft followed by NK cell activation and release of the DC maturation factor HMGB1. Blood 2005; 106: 609-616.

81. Semino C, Ceccarelli J, Lotti LV, Torrisi MR, Angelini G, Rubartelli A. The maturation potential of NK cell clones toward autologous dendritic cells correlates with HMGB1 secretion. J Leukoc Biol 2007; 81: 92-99.

82. Balsamo M, Zambello R, Teramo A, Pedrazzi M, Sparatore B, Scordamaglia F et al. Analysis of NK cell/DC interaction in NK-type lymphoproliferative disease of granula lymphocytes (LDGL): role of DNAM-1 and NKp30. Exp Hematol 2009; 37: 1167-1175.

83. Naghavi MH, Nowak P, Andersson J, Sonnerborg A, Yang H, Tracey KJ et al. Intracellular high mobility group B1 protein (HMGB1) represses HIV-1 LTR-directed transcription in a promoter- and cell-specific manner. Virology 2003; 314: 179-189.

84. Thierry S, Gozlan J, Jaulmes A, Boniface R, Nasreddine N, Strauss F et al. High-mobility group box 1 protein induces HIV-1 expression from persistently infected cells. AIDS 2007; 21: 283-292.

85. Andoniou CE, van Dommelen SLH, Voigt V, Andrews DM, Brizard G, Asselin-Paturel C et al. Interaction between conventional dendritic cells and natural killer cells is integral to the activation of effective antiviral immunity. Nat Immunol 2005; 6: 1011-1019.

86. Mavilio D, Lombardo G, Kinter A, Fogli M, La Sala A, Ortolano S et al. Characterization of the defective interaction between a subset of natural killer cells and dendritic cells in HIV-1 infection. J Exp Med 2006; 203: 2339-2350.

87. Tasca S, Tambussi G, Nozza S, Capiluppi B, Zocchi MR, Soldini L et al. Escape of monocyte-derived dendritic cells of HIV-1 infected individuals from natural killer cellmediated lysis. AIDS 2003; 17: 2291-2298.

88. Alter G, Kavanagh D, Rihn S, Luteijn R, Brooks D, Oldstone M et al. IL-10 induces aberrant deletion of dendritic cells by natural killer cells in the context of HIV infection. J Clin Invest 2010; 120: 1905-1913.

89. Sims GP, Rowe DC, Rietdijk ST, Herbst R, Coyle AJ. HMGB1 and RAGE in inflammation and cancer. Annu Rev Immunol 2010; 28: 367-388.

90. Troseid M, Nowak P, Nystrom J, Lindkvist A, Abdurahman S, Sonnerborg A. Elevated plasma levels of lipopolysaccharide and high mobility group box-1 protein are associated with high viral load in HIV-1 infection: reduction by 2-year antiretroviral therapy. AIDS 2010; 24: 1733-1737.

91. Barqasho B, Nowak P, Abdurahman S, Walther-Jallow L, Sonnerborg A. Implications of the release of high-mobility group box 1 protein from dying cells during human immunodeficiency virus type 1 infection in vitro. J Gen Virol 2010; 91: 1800-1809.

92. Brenchley JM, Price DA, Schacker TW, Asher TE, Silvestri G, Rao S et al. Microbia translocation is a cause of systemic immune activation in chronic HIV infection. Nat Med 2006; 12: 1365-1371.

93. Marchetti G, Cozzi-Lepri A, Merlini E, Bellistrì GM, Castagna A, Galli M et at. ICONA Foundation Study Group. Microbial translocation predicts disease progression of HIV-infected antiretroviral-naive patients with high CD4+ cell count. AIDS 2011; 25 1385-1394.

94. Zhu P, Duan L, Chen J, Xiong A, Xu Q, Zhang H et al. Gene silencing of NALP3 protects against liver ischemia-reperfusion injury in mice. Hum Gene Ther 2011; 7.

95. Bianchi ME. HMGB loves company. J Leukoc Biol 2009; 86: 573-576.

96. Murua Escobar H, Meyer B, Richter A, Becker K, Flohr AM, Bullerdiek J et al. Molecular characterization of the canine HMGB1. Cytogenet Genome Res 2003; 101 33-38.

Andoniou CE, van Dommelen SLH, Voigt V, Andrews DM, Brizard G, Asselin-Paturel C et al. Interaction between conventional dendritic cells and natural killer cells is integral to the activation of effective antiviral immunity. Nat Immunol 2005; 6: 1011-1019. In vivo study showing that the control of MCMV infection requires NK-DC interaction, NK cytotoxicity and IFN-gamma production depending on IFN-alpha and DC-derived IL-18 respectively.

Melki MT, Saidi H, Dufour A, Olivo-Marin JC, Gougeon ML. Escape of HIV-1-Infected Dendritic Cells from TRAIL-Mediated NK Cell Cytotoxicity during NK-DC Cross-Talk-A Pivotal Role of HMGB1. Plos Pathog 2010; 6: e1000862. New strategy developed by HIV-1 to escape immune attack, involving HMGB1-mediated upregulation of anti-apoptotic molecules in DCs, thus becoming resistant to NK killing.

Izquierdo-Useros N, Naranjo-Gomez M, Archer J, Hatch SC, Erkizia I, Blanco J et al. Capture and transfer of HIV-1 particles by mature dendritic cells converges with the exosomedissemination pathway. Blood 2009; 113: 2732-2741. A new potential viral dissemination pathway is highlighted, showing that HIV-1 can exploit the exosome antigendissemination pathway intrinsic to mature DCs for mediating trans-infection of $T$ lymphocytes.

Brenchley JM, Price DA, Schacker TW, Asher TE, Silvestri G, Rao S et al. Microbial translocation is a cause of systemic immune activation in chronic HIV infection. Nature Med 2006; 12: 1365-1371. Proposal of a new mechanism for the chronic activation of the immune system, a hallmark of progressive HIV infection, possibly due to circulating microbial products derived from the compromised gastrointestinal mucosal surface in infected patients. 